Marshall University

Marshall Digital Scholar

Biological Sciences Faculty Research

Biological Sciences

Spring 4-1-2008

\title{
Inferences regarding the diet of extinct hominins: structural and functional trends in dental and mandibular morphology within the hominin clade
}

Peter W. Lucas

Paul J. Constantino

Biological Sciences, paulconstantino@gmail.com

Bernard A. Wood

Follow this and additional works at: http://mds.marshall.edu/bio_sciences_faculty

Part of the Biological and Physical Anthropology Commons

\section{Recommended Citation}

Lucas PW, Constantino P, and Wood BA. Inferences regarding the diets of extinct hominins: structural and functional trends in masticatory morphology within the hominin clade. Journal of Anatomy 212: 486-500.

This Article is brought to you for free and open access by the Biological Sciences at Marshall Digital Scholar. It has been accepted for inclusion in Biological Sciences Faculty Research by an authorized administrator of Marshall Digital Scholar. For more information, please contact zhangj@marshall.edu, martj@marshall.edu. 


\title{
REVIEW
}

\section{Inferences regarding the diet of extinct hominins: structural and functional trends in dental and mandibular morphology within the hominin clade}

\author{
Peter W. Lucas, Paul J. Constantino and Bernard A. Wood \\ Department of Anthropology, George Washington University, Washington, DC, USA
}

\begin{abstract}
This contribution investigates the evolution of diet in the Pan-Homo and hominin clades. It does this by focusing on 12 variables (nine dental and three mandibular) for which data are available about extant chimpanzees, modern humans and most extinct hominins. Previous analyses of this type have approached the interpretation of dental and gnathic function by focusing on the identification of the food consumed (i.e. fruits, leaves, etc.) rather than on the physical properties (i.e. hardness, toughness, etc.) of those foods, and they have not specifically addressed the role that the physical properties of foods play in determining dental adaptations. We take the available evidence for the 12 variables, and set out what the expression of each of those variables is in extant chimpanzees, the earliest hominins, archaic hominins, megadont archaic hominins, and an inclusive grouping made up of transitional hominins and pre-modern Homo. We then present hypotheses about what the states of these variables would be in the last common ancestor of the Pan-Homo clade and in the stem hominin. We review the physical properties of food and suggest how these physical properties can be used to investigate the functional morphology of the dentition. We show what aspects of anterior tooth morphology are critical for food preparation (e.g. peeling fruit) prior to its ingestion, which features of the postcanine dentition (e.g. overall and relative size of the crowns) are related to the reduction in the particle size of food, and how information about the macrostructure (e.g. enamel thickness) and microstructure (e.g. extent and location of enamel prism decussation) of the enamel cap might be used to make predictions about the types of foods consumed by extinct hominins. Specifically, we show how thick enamel can protect against the generation and propagation of cracks in the enamel that begin at the enameldentine junction and move towards the outer enamel surface.
\end{abstract}

Key words biomechanics; dentition; enamel; function; mechanics.

\section{Introduction}

If you know the diet of an extant primate taxon, it is possible to predict a good deal about its natural history and morphology. Conversely, if you know enough about the natural history and morphology of an extant primate taxon, you can make quite precise inferences about its diet. If, however, the primate taxon is extinct, not extant, then dietary inferences are far more challenging. The evidence available about the natural history of an extinct primate taxon is indirect and is therefore much more 'broad brush' (see Elton, this issue, for a review of attempts to reconstruct the paleoenvironment of extinct hominins).

Correspondence

Dr Peter Lucas, CASHP, Department of Anthropology, George

Washington University, Washington DC, USA. T: +1 202994 6964;

F: +1 202994 6097; E: pwlucas@gwu.edu

Accepted for publication 22 February 2008
Information about morphology has to come from whatever survives of individual members of the taxon, and what the fossil record of each taxon consists of is determined by a complex mix of predator behaviour, tissue durability and the many other factors that result in differential preservation of the skeleton. Nonetheless, although students of the diet of extinct hominins (and we are no exception) ritually complain about the paucity of the available evidence, we are much better served by the fossil record than, say, those who attempt to reconstruct the language and social behaviour of extinct hominin taxa (see Sherwood et al. 2008).

We were asked by the organizers of the 2007 ASGBI Human Evolution Symposium to make predictions about the diet of the hypothetical last common ancestors (LCAs) of the hominin/panin and hominin clades. We were also asked to trace the subsequent evolution of dietary adaptations within the hominin clade, and then speculate about when in hominin evolution the dietary adaptations 
Fig. 1 Hominin fossils, as arranged as Wood (2002), and grouped in morphological clusters. H., Homo; A., Australopithecus; $P$., Paranthropus. The other names for hominin genera are spelt out in full. The horizontal scale is qualitative, serving partly to space the fossils, but also to indicate approximate relationships. The main line of descent, which may miss all known fossils, runs lower right to upper left.

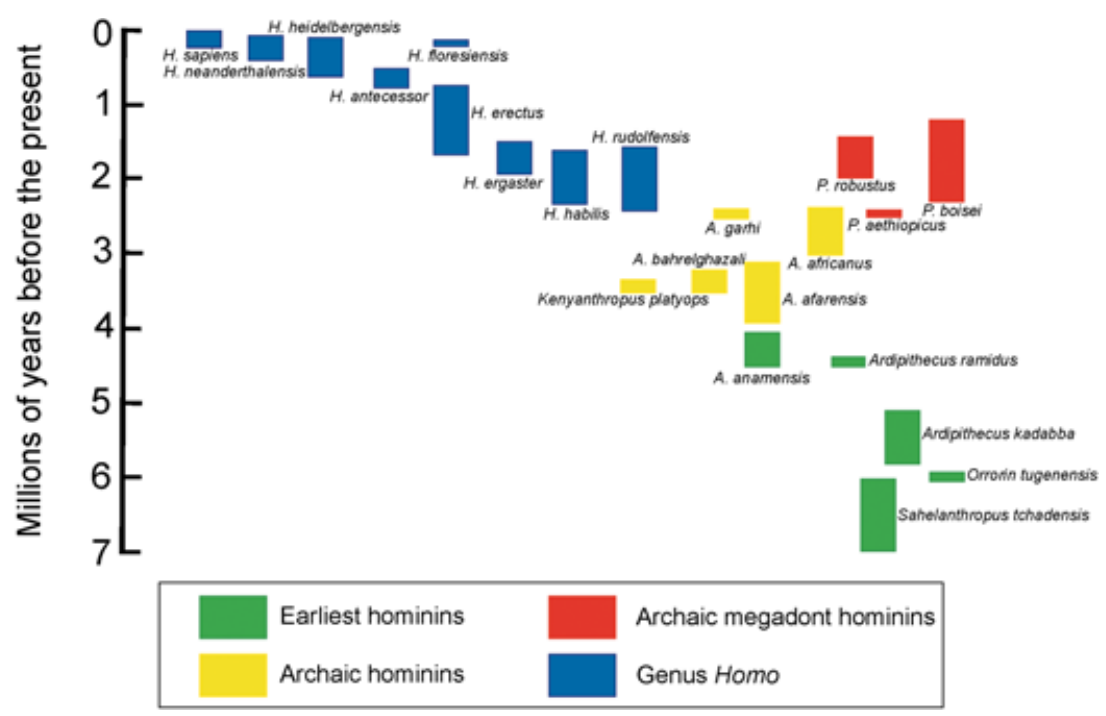

of modern humans appeared. There are many lines of evidence [e.g. dental and gnathic (i.e. upper and lower jaws) morphology, functional analysis, dental microwear, stable isotopes, archeology, referential and analogical extant models, etc.] that can be used to help reconstruct the diets of extinct hominins, and these have been fully and effectively summarized in recent reviews, some of them book-length (e.g. Teaford \& Ungar, 2000; Ungar \& Teaford, 2002; Ungar, 2007). It is neither possible nor desirable to reprise all of these lines of evidence in this contribution, so we have a more modest agenda. We focus on 12 variables (nine dental and three mandibular) for which data are available about extinct hominins (Table 1). For some hominin taxa (e.g. Australopithecus afarensis, Paranthropus boisei, Homo neanderthalensis) the fossil record is good enough for us to have data about all of the variables, but for many early hominin taxa with relatively sparse fossil records (e.g. Ardipithecus ramidus, Australopithecus garhi) relatively few data are available, and for some of the variables the evidence is either non-existent, or the samples are so small that the sample parameters are unreliable guides to the characteristics of the taxon. We take the available evidence for some of the nine dental variables and review the relevant literature, some of it very recent and outside evolutionary biology. The combination of the morphological evidence and the new insights prompted by developments in cognate research areas have enabled us to suggest new avenues of research that could shed light on how these morphological data can be used to generate testable hypotheses about the dietary adaptations of extinct hominins.

One of us has recently argued (Lucas, 2004) that researchers should take a fresh look at the way morphological information about the dentition is used to make dietary inferences. Previous analyses had focused on the identification of the food consumed (i.e. fruits, leaves, etc.) rather than on its physical properties (i.e. hardness, toughness, etc.), and they had not specifically addressed the role that the physical properties of foods play in determining dental adaptations. Similarly, the fracture mechanics of foods, which are fundamental to dental-dietary interactions, were rarely if at all addressed. In this paper we show that some of the enigmas about the dietary adaptations of early hominins might be resolved if the analysis is moved beyond the descriptive level to incorporate recent advances in mechanics.

\section{Hominin fossil record}

There are currently many hominin species recognized in some of the more speciose taxonomic hypotheses (Fig. 1; and see Wood \& Lonergan, 2008), and the situation in hominin systematics is far from static. For example, the status of Homo ergaster as an East African form of early Homo may soon be revised and the recently discovered evidence for the long-term sympatry of $H$. ergasterlerectus and Homo habilis in East Africa suggests that $H$. habilis may not necessarily be a good model for the morphology of the earliest Homo, being at least partly an adaptive response to the presence of another Homo species (Spoor et al. 2007). Consequently, it seems unwise at the present time to try to identify dietary adaptations within the hominin clade at the species level. This is not to say that such an endeavour is impossible in functional terms, but we believe that at the moment such attempts invite premature obsolescence. Therefore, we will discuss dietary adaptations in extinct fossil hominins in terms of four inclusive grade groupings:

(1) Earliest hominins (coloured green in Fig. 1) ranging from 7 to $4 \mathrm{Ma}$. This group includes Sahelanthropus tchadensis, the earliest potential hominin yet found, Orrorin tugenensis, Ardipithecus kadabba and Ar. ramidus. There 
Table 1 General trends in hominin dental and gnathic morphology

\begin{tabular}{|c|c|c|c|c|c|c|c|c|}
\hline Morphological trait & Pan troglodytes & LCA & Stem hominin & Earliest hominins & Archaic hominins & Archaic megadonts & Pre-modern Homo & Homo sapiens \\
\hline \multicolumn{9}{|l|}{ DENTITION } \\
\hline Incisor size & large & large & $\operatorname{large*}$ & medium & medium & small & medium & medium \\
\hline Incisor orientation & procumbent & procumbent & procumbent & procumbent (?) & procumbent & vertical & vertical & vertical \\
\hline Incisor to postcanine ratio & high & high & medium & medium & medium & low & medium & medium \\
\hline Canine size & large & large & medium & medium & medium & small & small & small \\
\hline Canine sexual dimorphism & high & high & moderate & moderate & reduced & low & low & low \\
\hline Relative premolar size $\left(\mathrm{P}_{4} / \mathrm{M}_{2}\right)$ & small & small & small & small & mediumt & large & medium & medium \\
\hline Molar size & small & small & medium & medium & large & very large & small & small \\
\hline Molar size gradient & M2 largest & M2 largest & M2 largest & M2 largest & M2 largest & M3 largest & variable & M1 largest \\
\hline Enamel thickness & thin & thick $\neq$ & thick $\ddagger$ & thin & thick & hyper-thick & thick & thick \\
\hline \multicolumn{9}{|l|}{ MANDIBLE } \\
\hline Mandibular corpus height (h) at M1 & tall & tall & moderately tall & $?$ & moderately tall & very tall & short & short \\
\hline Mandibular corpus breadth (b) at M1 & slightly broad & slightly broad & slightly broad & slightly broad & broad & very broad & broad & narrow \\
\hline Mandibular robusticity at M1 (b/hX100) & gracile & gracile & slightly robust & $?$ & moderately robust & very robust & robust & gracile \\
\hline
\end{tabular}

Predictions for the last common ancestor (LCA) of modern humans and chimpanzees and the stem hominin are shown in italics.

'Earliest' = Sahelanthropus, Orrorin and Ardipithecus, 'Archaic' = Australopithecus, 'Megadont' = Paranthropus, and 'Early Homo' = Homo habilis, H. rudolfensis, H. ergaster and H. erectus.

Data from Brown \& Walker (1993), Gabunia \& Vekua (1995), Plavcan \& Van Schaik (1997), Asfaw et al. (1999), Ward et al. (2001), Brunet et al. (2002), Brunet et al. (2005), and Moggi-Cecchi et al. (2006).

*Predicted to be large because Sahelanthropus has large incisors, while the later Ardipithecus does not.

tDoes not include the large-premolared $A$. garhi.

$\neq$ See text for explanation. 
is still relatively little known about the dental and gnathic morphology of all of these taxa.

(2) Archaic hominins (coloured yellow in Fig. 1) ranging from 4 to $2.5 \mathrm{Ma}$. This group includes taxa such as $A$. afarensis and $A$. africanus with substantial dental and gnathic fossil records.

(3) Archaic megadont hominins (coloured red), ranging from about 2.5 to $1.1 \mathrm{Ma}$. The two species with the best fossil records are the East African hyper-robust species, P. boisei, and the southern African species, Paranthropus robustus. The dental and gnathic morphology of both species is well known.

(4) Pre-modern Homo (blue), ranging from about $2 \mathrm{Ma}$ to approximately $18 \mathrm{ka}$. The dental and gnathic gestalt is broadly similar in these taxa although there are substantial differences in overall tooth size within this grouping.

Table 1 lists the 12 dental and mandibular traits and gives the expressions of those traits for each of the above hominin groupings, and its predicted states in (a) the stem hominin, (b) the LCA of the combined hominin and panin clades and (c) the observed state in both living common chimpanzees and modern humans.

\section{Dental and gnathic characteristics of the LCA of Pan-Homo}

In most aspects, it is probably wisest to assume that the dentition of the LCA of chimpanzees/bonobos and hominins resembled that of the modern common chimpanzee. The incisors were likely to have been large and, when first erupted, procumbent (i.e. with the occlusal margins of the sloping crowns projecting forwards). The canines were sexually dimorphic, with much more projection beyond other teeth in males than females (as is true of all great apes; see Lucas et al. 1986b). The premolar crowns were relatively small, with the largest of the molars being the second (M2), as is also true of the other great apes. Haile-Selassie et al. (2004) suggest that the upper canine of Ardipithecus had its posterior edge sharpened against an anterior extension of the anterior lower premolar (P4), as in great apes and most Old World and New World monkeys (Zingeser, 1969). The only characteristic that might vary from this inferred chimplike form is the thickness of enamel over the postcanine teeth. It is entirely possible that modern chimpanzees have reduced the thickness of their enamel (Vogel et al. in press), just as it is possible that modern gorillas may have done (Suwa et al. 2007). This makes enamel thickness an important character for functional analysis, as it is under genetic control (Hlusko et al. 2003), yet it is apparently quite labile and responsive to selective pressures (Hlusko, 2004).

\section{Dental differences among hominin taxa}

The dental differences among the actual and predicted taxa are set out in Table 1 . In the section that follows we make specific comments about either the state of the morphology as observed in a specific extant or extinct taxon, or the predicted state of the morphology in an as yet hypothetical taxon.

\section{Incisors}

The incisors were probably also procumbent on eruption in both the earliest and archaic hominins (Asfaw et al. 1999). However, archaic megadont hominins, along with members of the genus Homo, had more vertically implanted and relatively smaller incisors (McHenry, 2002). Incisal reduction in the archaic megadonts was coupled with enlargement of the premolars and molars (Grine, 1981).

\section{Canines}

In the earliest hominins, the canine teeth are said to have been relatively small (see Brunet et al. 2002 for information about $S$. tchadensis), and further size reduction continued within this time period (Haile-Selassie et al. 2004). The greatest relative canine reduction is seen in the megadont archaic hominins, but there is some evidence that the premolars and molars are abnormally large in these taxa, especially when compared with the relatively modest size of the canine (Wood \& Stack, 1980).

\section{Molars}

The second molars were generally the largest of the molar teeth in the earliest and in the archaic hominins, but there was a distinct tendency for $M 3$ to be as large, if not the largest, of the molars particularly with respect to the mandibular dentition of the archaic megadonts (Wood \& Abbott, 1983; Wood et al. 1983; Wood, 1984). In modern Homo, the first molar is usually the largest of the molars (van Reenen, 1982; Townshend \& Brown, 1983), following extensive reduction in overall tooth size (Brace et al. 1987). Hominins all tend to have low blunt cusped molars and premolars - the so-called bunodont type of dentition. It is generally agreed that the earliest hominins to have had thick enamel were the archaic hominins (Martin, 1985), and that enamel became even thicker in the 'hyperthick' archaic megadonts (Beynon \& Wood, 1987; Grine \& Martin, 1988). Even in modern humans, the enamel of the postcanine teeth is much thicker than in the equivalent teeth of the extant apes (Kono, 2004; Smith et al. 2005).

\section{Food physics}

We suggest that these observations can best be explained against a knowledge of the physical properties of the ingested foods. Two aspects of the physical properties of foods exert a strong influence on tooth form. Their external physical characteristics, which describe the form of the 
external surface of the food item, and its internal mechanical properties. These are the properties of a food that determine how resistant the food is to being fractured (Lucas et al. 1986c). Food fracture creates larger external surface areas, and thus the external physical characteristics of a food are always in flux inside the mouth as the food is broken down. However, unless food dissolves in the mouth, melts, is acted on by enzymes or else undergoes a deformation transition (see later in this section), its internal mechanical properties will remain the same.

When a food particle is loaded by a force, that force creates stresses in the particle (a stress is a force divided by the area over which it acts). These stresses may cause the particle to deform. The extent of such deformation in the direction of the force can be normalized to the size of the particle to produce another size-independent variable, called strain. In foods where the stress is more or less proportional to the strain, at least initially, the most important property that defines the ease of deformation is simply the stress/strain ratio. This ratio is called the Young's (or the elastic) modulus, and is usually symbolized as $E$. Once a particle fractures, then its most important property is its toughness, $R$, which is defined as the energy expended during the growth of a crack of unit area.

But things are not always so straightforward. Foods can have complex microstructures with consequent anisotropy (variation in properties with the direction of loading), and they also often do not have strain proportional to stress at any point during loading. Foods with these more complex physical properties stretch the capacity of current methods of analysis in materials science. Nevertheless, Ashby (1989, 1999) defined two indices that have an important bearing on the fracturability of foods that exhibit approximately linear behaviour. He suggested that when the force is limiting, the quantity $(E R)^{0.5}$ effectively defines the resistance of foods to fracture, and when deformation is limiting, it is $(R / E)^{0.5}$. Lucas et al. (2000) give a simple illustration of such force and displacement limitations and adopted these indices as a way of looking at the behaviour of plant tissues under different loading conditions.

As plant foods have dominated much of the debate about primate diets, and because the ingestion of plant foods has featured in some hominin dietary adaptive scenarios, these indices could aid our consideration of such scenarios. Lucas et al. (2000) suggested that $(E R)^{0.5}$ is very close to what is understood by biologists as 'hardness', while the quantity $(R / E)^{0.5}$ is close to what biologists term 'toughness'. There is some evidence from feeding experiments in modern humans that these quantities apply to foods being loaded by the dentition (Agrawal et al. 1997, 1998, 2000; Lucas et al. 2002; Vincent et al. 2002; Agrawal \& Lucas, 2003).

Those used to more traditional accounts of mechanics may not follow this and wonder where, for example, fracture stress comes into the discussion. The problem with fracture stress as an independent fracture-controlling parameter is that its value is dependent on intrinsic flaws in a material. The larger the flaws, the lower the fracture stress (Griffith, 1920; Atkins \& Mai, 1985; Lawn, 1993). In fact, fracture stress depends roughly on $(E R / C)^{0.5}$, where $c$ is the length of the largest flaw. In general, results from materials testing suggest that the larger the specimen, the lower the strength because the larger the flaw sizes present within it (Atkins \& Mai, 1985; Kendall, 2001). Thus, fracture stress is not a basic parameter, but a variable that depends on $E$ and $R$. A materials scientist may measure toughness as $R$. In a mechanical test, $R$ is isolated by factoring out any elastic deformation not used in crack growth. However, in any practical loading situation, energy is stored via elastic deformation, and thus it is the ratio of $R$ to $E$ that matters in any practical assessment of 'toughness'.

Even more confusingly, some materials scientists measure toughness as $(E R)^{0.5}$, a parameter that may be symbolized as $K$ or $T$ (Lawn, 1993). Calling $(E R)^{0.5}$ here the scientific colloquial equivalent of hardness reflects our opinion that 'hard foods' in the hominin and primate literature are very often those with a high $(E R)^{0.5}$. Foods described in the literature as 'tough' nearly always have a high $R$ to $E$ ratio.

Materials scientists do not define hardness as $(E R)^{0.5}$. For them, hardness $(H)$ is an indirect measure (obtained via empirical indentation) of the boundary between elastic behaviour that produces recoverable deformations after a load is removed, and plasticity which is when a permanent change in external dimensions is observed. The stress at the boundary between these behaviours is thought to be a fundamental property and is termed the yield stress $(Y)$. It is a feature of solids that their behaviour changes with respect to their particle sizes at a threshold in size (linear measurement) given by $(E R)^{0.5} / Y$ (Kendall, 2001), sometimes written as $K^{2} / H^{2}$, with $H=3 Y$ for many materials (Lawn, 1993). This threshold is called the 'deformation transition' (Atkins \& Mai, 1985), and is of great potential importance in understanding the evolution of dental macrostructure and microstructure (Agrawal et al. 2008). There are constants of proportionality involved in construction of precise relationships for all the above, but the emphasis here is only on the dimensional form of these relationships.

Going back to the definitions of Lucas et al. (2000), it is clear that a food cannot be both hard and tough. In practice, hard foods with a high $(E R)^{0.5}$ are dominated more by a high $E$ than a high $R$. In fact, $R$ in hard objects is often very low, although it need not be. In contrast, tough foods with a high $(R / E)^{0.5}$ are dominated generally by high $R$ and usually by a low $E$.

\section{Tooth shape}

The foregoing analysis is useful for understanding the potential for crack formation in foods with different internal mechanical properties. Dentitions designed to break down hard foods look very different from those that are 
designed to break down tough foods (Lucas, 2004). Tough foods are very difficult to fragment (i.e. to fracture into separable pieces) without very sharp features on tooth crowns. Due to their usually low modulus (low $E$ ), the areas of teeth in contact with such food particles are extensive, and as the load is increased, the food particle spreads across the tooth. Sharp features are needed continually to re-initiate (re-sharpen) crack tips that otherwise tend to blunt, stop moving and frustrate fragmentation. Such crack tips may or may not jump slightly ahead of the sharp tooth feature that produces them - this depends on the level of $R / E$ and also on the microstructure of the food but their progress will always arrest quickly without the proximity of these sharp features. Such teeth are usually not pointed because cracks will not spread laterally. So, in order to subdivide such food particles, teeth need to have bladed features - sharp points that are extensive in one plane. In contrast, hard foods fragment very easily because $R$ is low. Contact areas stay small as the load is increased because of the high $E$ of such foods. Sharp features on teeth would be quickly lost because of the locally high energy densities that lead to fracture. Further, cracks spread laterally very easily. So, the design for teeth optimized to break down hard foods involves low, blunt points (i.e. what we refer to as 'cusps').

To summarize, foods with high values of $(E R)^{0.5}$ crack easily. The dentition of a mammal that consistently loads these hard foods with their molars is most likely to possess low, blunt cusps - the sort of postcanine dentition that all hominins have. In contrast, foods with high values of $(R /$ $E)^{0.5}$ are very resistant to cracking. The loads of such particles against teeth are generally spread out over large areas of the tooth crown surface localized because the modulus of the food is low and the high value of $R$ means that strains at failure will be high. The dentition of a mammal that consistently loads these tough foods with their molars is most likely to possess prominent blades (or crests) on their teeth.

\section{Ingestion - incisor function}

The first bite is a critical element of the feeding process. However, there have been remarkably few attempts at a tooth-food contact analysis. Despite this, a single bite is likely to have a much more stereotyped action and contact geometry than the ordered chaos of particle size reduction during mastication, and thus it should be simpler to analyse.

Most anthropoid primates differ from other mammals in having a broad 'spatulate' edge to their incisors. Anthropoids probably evolved in the Eocene as diurnal frugivores (Ross, 2000; Dominy, 2004). Spatulate incisors could have evolved quite early in relation to fruit eating (Lucas, 1989, 2004; Lucas \& Corlett, 1991). The argument rests on the characteristic covering of the fruits that primates eat as a minority of their diets in tropical rain forest - the fruit peel. Removing a thick peel involves controlling a crack along the peel-flesh interface. This can be difficult without the type of broad bladed edge that spatulate incisors have, and which can guide the crack along the interface. From the plant's point of view, this restricts access to its fruit from other frugivores and thus ensures they are subject to a particular pattern of seed dispersal that only the primates 'armed' with spatulate incisors have.

Much of the efficiency of spatulate incisors is considered to lie in the extent of their mesiodistal breadths (Hylander, 1975; Eaglen, 1984). Hylander (but not Eaglen) found that primates with more fruit in their diets often have broader incisors than those that concentrate on leaves. However, relating this finding to the physiological action of incisors is difficult because of the wide variety of other tasks for which they can be used (Osborn et al. 1987; Ungar, 1992).

Analysis of incisor function is made easier by boiling down these other activities to one of two distinct physical forms: generally, they either involve grip, or grip plus fracture (Lucas, 2004, et al. in press a; Ang et al. 2006). If the incisors are used solely for grip, then the coefficient of friction between the tooth surface and the plant part is all important. At a macroscopic level, friction is independent of the area of contact and thus narrower incisors serve just as well as broader ones. Many leaf-eating primates seem to use their incisors to grasp small branches, drawing these through the gap between the teeth to detach leaves (Ungar, 1996). The incisors grip the branches, but also allow them to slip. Broad incisal edges may not benefit these primates very much, suggesting that small incisors could represent an adaptation to a leaf-eating diet. In contrast, the rate of removal of the peel of a large fruit is a fracture activity and probably depends very much on the length of an incisal edge (i.e. the breadth measurement of spatulate incisors).

The incisors of anthropoids differ not just in their mesiodistal dimensions, but also in their heights (which are undoubtedly related to wear rates) and in their orientation. This is particularly relevant to hominins. The incisors of the members of the genus Homo in particular are reported as being much closer to the vertical than those of great apes (McHenry, 2002). Incisal orientation does change with age, becoming more vertical (Lysell, 1958; Hylander, 1977; Dean et al. 1992), but perhaps this - as with dental features that wear - is unavoidable.

The influence of incisal orientation on the efficiency of incisor use is still best seen in the form of a fracture mechanics analysis of the tip of the incisal crown with respect to crack tips, and this is due to Ang et al. (2006). In this analysis the optimal orientation of the incisal edge to the surface of the object to be incised is not necessarily vertical. Ang et al. (2006) suggest that this depends primarily on the coefficient of friction involved. If friction is low, then the optimal angle could be markedly inclined to the food surface - an orientation that equates to procumbency - 

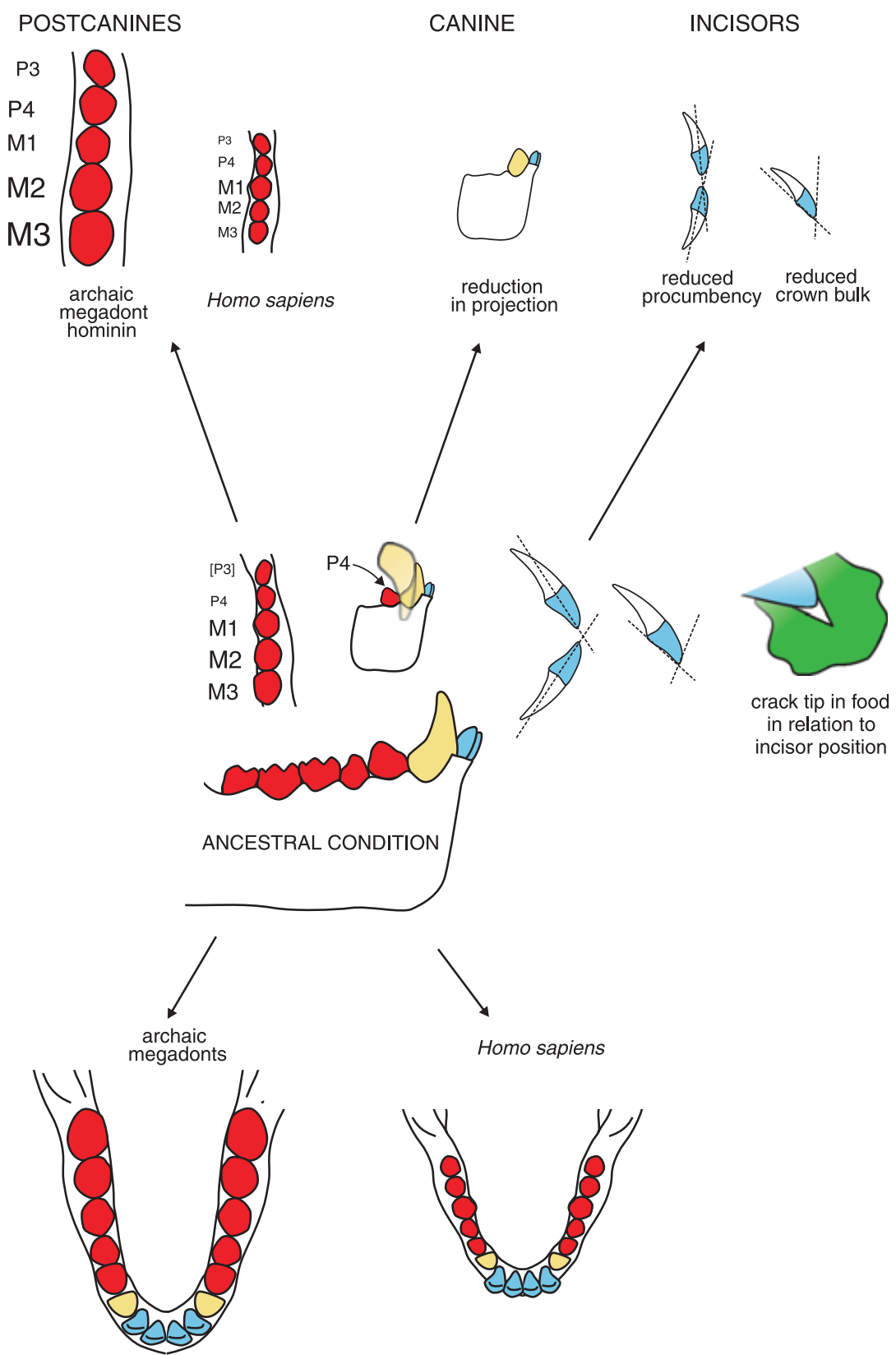

while if friction is high, more vertically implanted incisors are definitely favoured.

\section{Protection against the fracture of tooth parts}

The incision analysis of Ang et al. (2006) provides some support for the results of the experiments of Sui et al. (2006), which suggest that the greater the toughness, the higher is the force required during food fracture. The potential for these forces instead to produce fracture of the incisal crown can be resisted by bulking up the crown (Fig. 2).

Until wear exposes the dentine, it is the outermost tissue, the enamel, which actually contacts food particles, their inedible coverings (such as peels and seed shells) and/or
Fig. 2 Schematic view of size trends in the permanent dentition during hominin evolution susceptible to functional analysis, illustrated by archaic megadonts and modern humans as dental extremes. Postcanines are shown in red, canines in yellow and incisors in blue. Incisors have generally reduced in size, procumbency and bulk. Permanent canines were reduced in the earliest hominins, while postcanines expanded in archaic megadonts, but reduced in the genus Homo. The lower diagrams contrast the long, narrow tooth rows of archaic megadonts with the short, wide row of modern humans. any grit associated with them. As such, the properties, structure, dimensions (particularly the thickness) and the overall shape of the enamel cap of tooth crowns must be the subject of intense selective pressure. It is a general feature of sharp-bladed (or crested) postcanine teeth that the enamel that covers them is quite thin, the sharpness being generated by the enamel ridge standing proud of the dentine. In contrast, the low, blunt cusps typical of most hominin postcanine teeth are coated with relatively thick enamel.

Mammalian enamel is the most heavily mineralized tissue of the body, and it provides a durable coat over the tooth crown which is otherwise made up of a dentinal core (Osborn, 1981). Yet, enamel does not last forever. The 

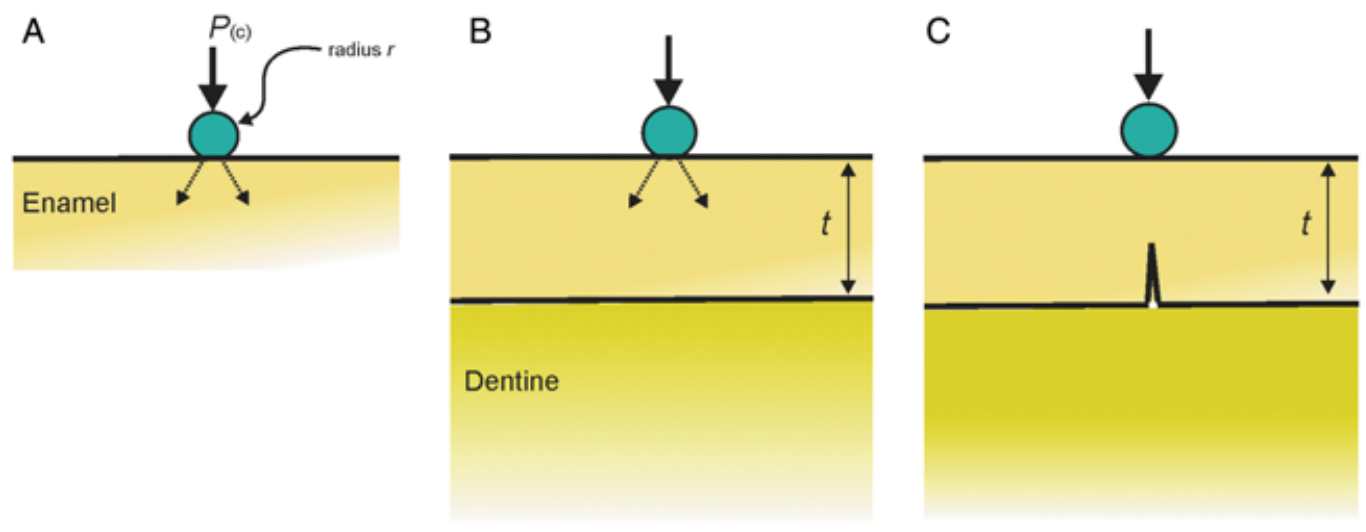

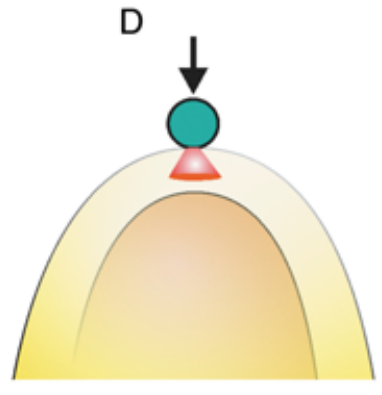

surface fracture

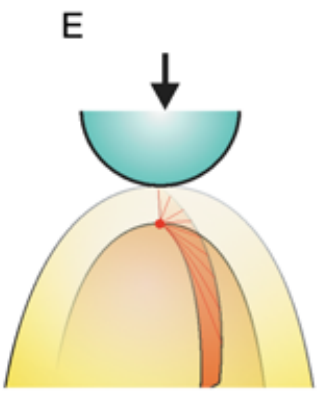

deep (radial) fracture

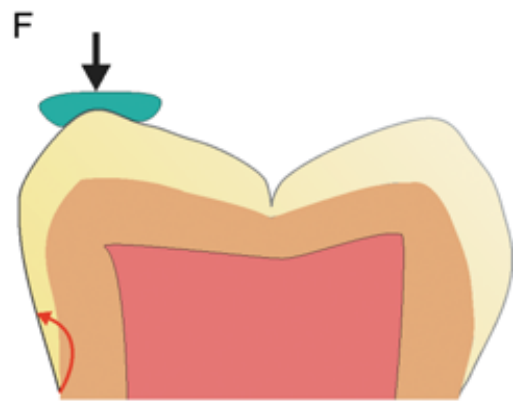

abfraction

Fig. 3 Explanation of the adaptive value of enamel thickness. (A) The loading $F$ endured by enamel [pictured in (B) and (C) with a thickness $t$ ] produced by a spherical particle of effective radius $r$. (D-F) The types of cracking behaviour likely to result. (D) A cone crack. In (E), the crack actually starts deep from the enamel-dentine junction and runs up to the surface. In (F), the crack starts around the cervical margin of the tooth (where the enamel meets the cement) and may result in a fragment falling from the side of the tooth. See text.

thickness of the enamel is very variable in primates. Several groups of extinct primates, including Miocene apes, had thick enamel, and in at least some groups, hard object feeding has been linked to this pattern (Martin et al. 2003; Smith et al. 2003; Godfrey et al. 2004). Thus, enamel thickness may be a crucial characteristic for understanding hominin dietary evolution.

The following theory is a brief version of the arguments set out in Lucas et al. (in press b), and this in turn is based on a series of papers on the physics of bilayered solids due to Lawn (the landmark papers are: Lawn, 1993; Lawn et al. 2001; Rhee et al. 2001; Rudas et al. 2005; Qasim et al. 2007). There are two hypotheses about why enamel might be thickened in some mammals: (1) that it strengthens the tooth crown in mammals that feed on hard objects (Kay, 1981) or (2) that it provides extra wear potential, thus extending the life of the tooth (Molnar \& Gantt, 1977). Food hardness is often taken as the key component of wear resistance in both theories, but the most important point here is that contacts between hard food objects and teeth are going to result in small (concentrated) areas of loading.

The first theory has attracted most support, but Fig. 3 shows why, at first glance, it does not look very reasonable. Consider a flat isotopic 'enamel' surface contacted by a hard particle of effective radius $r$ (Fig. 3A,D). A 'cone crack' is forming beneath the contact in the enamel (this is basically true for both static and sliding contacts, see Lawn, 1967, 1993). This crack grows stably with a rising force given by

$P_{c}=C_{1} R r$

where $R$ is the enamel toughness (in $\mathrm{J} \mathrm{m}^{-2}$ ) and $C_{1}$ is a dimensionless constant (Lawn et al. 2001). This formula changes not at all if, as in Fig. 3B, this surface crack is considered to be growing in an enamel coat, of thickness $t$, on a dentinal base.

There have been various attempts to model surface damage as in wear, but none of them involves coat thickness (Sharp et al. 1993). So is the 'thicker is stronger' theory wrong? The answer is not necessarily. Most teeth consist of a relatively thin, stiff enamel coat laid over a much more compliant core made from primary dentine. In fact, the dentine found for $\sim 100 \mu \mathrm{m}$ directly under the enamel, the mantle dentine, is probably more compliant than the rest (Osborn, 1969; Renson \& Braden, 1971). The 'design secret' is in varying the loading regime to match the properties of food objects. Hard food objects will 
make small areas of contact with teeth. Under concentrated loading on a bilayered structure, the thin coat can easily bend on its compliant support and start to crack on its undersurface, i.e. at the enamel-dentine junction (EDJ) (Fig. 3C,E) (Lawn et al. 2001). As stated by Lucas et al. (in press $b$ ), one way to understand this is to rest a glass microscopic coverslip on a piece of elastic foam and press from above on the centre of the coverslip with a pencil tip. The glass will break easily, but via a crack initiating from its undersurface. The force for the initiation of these deep 'radial' cracks is given by

$P_{i}=\mathrm{C}_{2} \sigma_{\mathrm{F}} t^{2} / \log \left(E_{\mathrm{E}} / E_{\mathrm{D}}\right)$

where $\sigma_{\mathrm{F}}$ is the enamel fracture stress, $t$ is the enamel thickness, $E_{\mathrm{E}}$ is the Young's modulus of enamel while $E_{\mathrm{D}}$ is the dentinal modulus and $C_{2}$ is a dimensionless constant depending on the curvature of the enamel surface (Rhee et al. 2001; Rudas et al. 2005). Some points can be made immediately. For hard food objects, the enamel strain energy that can lead to fracture is localized under the point of contact. The highest stress lies at the EDJ. While the strength of the enamel is taken as a constant in Eq. (2), the force at which the enamel cracks rises as the square of its thickness. The enamel thickness here would be measured simply by dropping a line from the point of contact to the EDJ in the direction of the force. This method (Molnar \& Gantt, 1977; Beynon \& Wood, 1987; Kono, 2004) has now fallen out of favour somewhat because it is subject to error in orientating sections properly for measurement (Martin, 1985; Smith et al. 2005); however, inaccurate though some of the measurements may be, this 'plumb line' type of measure is clearly what is relevant to hard object feeding.

Lawn and co-workers have shown that deep 'radial' cracking is more complex than this. Deep cracks tend to arrest with the force to make them grow catastrophically towards the surface (Rudas et al. 2005) being

$P_{f}=\mathrm{C}_{3}(E R)^{0.5} t^{1.5} / \log \left(E_{\mathrm{E}} / E_{\mathrm{D}}\right)$.

The above is all limited to concentrated loadings (Fig. 3D,E), such as those that a food object with a high modulus might produce. A major difference between chewing on a large food item with a high modulus versus one that has a much lower value is that when the latter is loaded, it will tend to wrap around the tooth and thus distribute the load over a larger surface area (Fig. 3F). This has been shown to result in tensile stresses spreading round to the margin of the crown (Qasim et al. 2007). These result in fractures dentists call 'abfractions', wherein the sides of the tooth crown fracture (Fig. 3F) (Grippo, 1991). Note that in Eq. (3), while the dependence of the force on the enamel thickness is still there, the thickness exponent is less than for initiating cracks.
Several points emerge directly from the above. Restricting consideration to 'blunt' contacts on hard objects, a comparison of force calculations in Eqs (1) and (2) gives, for any given enamel thickness, a predicted food particle size at which a transition between a surface crack and a deep ('radial') crack might be found. For Eq. (1), we take $\mathrm{C}_{1}=8600$ (Lawn et al. 2001) and $R=13 \mathrm{~J} \mathrm{~m}^{-2}$ for enamel between the rods (Rasmussen et al. 1976), while in Eq. (2), $C_{2}=2$ (Lawn et al. 2001), $\sigma_{\mathrm{F}}=30 \mathrm{MPa}$ (Waters, 1980), $t=$ $1.5 \mathrm{~mm}$ (to take some initial thickness relevant to hominin evolution), $E_{\mathrm{E}}=90 \mathrm{GPa}$ and $E_{\mathrm{D}}=20 \mathrm{GPa}$ (He et al. 2006). We predict that, in contacts with small food particles of $r<5 \mathrm{~mm}$, enamel is likely to crack on its external surface. It would certainly crack that way against small objects like grass seeds, quartz grit or phytoliths. If particles are larger, though, then it seems more probable that cracks will start from the EDJ. This calculation is consistent with microwear data, where the diameters of the enamel features, be they pits or scratches, are generally of micrometre scale (Teaford, 1988, 1994). The damage caused by larger hard objects to enamel may be deep and, thus, not visible.

Thus, it can be concluded that a mammal feeding on small hard objects, or on a diet that contains lots of grit or phytoliths, may need thick enamel to extend tooth life, whereas a mammal feeding on larger hard objects may need thick enamel to increase the force at which internal, EDJ, cracks are initiated. In this sense, both of the theories seeking to explain enamel thickness may be correct; they just apply to different diets. This might explain why some large object feeders such as sea otters do not tend to show especially marked surface wear (Walker, 1981). In contrast, hominin postcanine teeth tend to show evidence of extensive wear (Grine, 1981; Kay \& Grine, 1988; Scott et al. 2005; Ungar et al. 2006).

A comparison of forces in Eqs (2) and (3) is instructive. Taking $C_{3}=60$ (Kim et al. 2007), and $R=13 \mathrm{~J} \mathrm{~m}^{-2}$ (Rasmussen et al. 1976; Okasaki et al. 1989) shows that the force required to make deep cracks grow is much greater than that required to start them off. Thus, cracks may form, but stall. It can be predicted that the teeth of hard object feeders may have enamel full of half-grown deep cracks. Just one loading event, one bite out of the thousands made per day, could produce such a deep crack, providing a permanent record of the load on a tooth.

\section{The role of enamel microstructure}

If such cracks are found in enamel, then it may be important for them to be stopped because of the selective pressure on enamel integrity discussed above. This is probably where the value of enamel microstructure comes in. Mammalian enamel contains elongate multi-crystalline structures called rods or prisms averaging several micrometres in width. At least partially bounded by organic sheaths, rods begin close to the dentinal junction coursing to close 
to the outer surface of the enamel cap. Sometimes straight, rods may also 'wave' in one plane. Further, the wave of adjacent rods is often slightly out of phase, with a progressive change across a region being dubbed rod 'decussation' (i.e. crossing). Such patterns are readily detected under the light microscope by an optical illusion whereby the enamel appears to be striped. Alternating light and dark stripes are called Hunter-Schreger bands, the width and spacing of which reflects the characteristics of the wave (Boyde, 1964; Osborn, 1973).

Decussation is a feature of the enamel of many mammals including hominins, and a wide variety of decussation patterns have been documented (von Koenigswald, 2000). In some primates, the enamel rods are always straight, an enamel pattern that is called radial (Martin et al. 2003). When decussation is seen, it is not always equally marked and there is a tendency in hominins for it to be restricted to the innermost enamel, next to the dentine, rather than near the outer surface of the enamel (Beynon \& Wood, 1987). This is not inevitable: decussation is seen close to, or on, the enamel surface in many herbivores (Rensberger \& von Koenigswald, 1980; Fortelius, 1985; Boyde \& Fortelius, 1986). The value of the decussation of the rods (prisms) in inner enamel is that it would help to stop cracks that arise at the EDJ. Given values for $R$ in the literature (Rasmussen et al. 1976; Okasaki et al. 1989), there is the possibility of a four-fold rise in the force required to fracture strongly decussated enamel compared with the radial form.

In addition, enamel thickness, measured at locations on a tooth where a load with a hard food is sustained (and we predict in hard-food eaters that these locations may have deliberately thickened enamel), provides a predicted maximum bite force on that tooth. This point is amplified below. A conservative guide of maximum bite force estimation is given by Eq. (2) because the enamel of the crown is damaged at the point by a crack initiating near to the EDJ. The upper limit at which the enamel fails catastrophically is that of Eq. (3). It should be noted such a catastrophe does not result in the fragmented crown of experiments such as those of Popowics et al. (2001, 2004): it is more likely to produce what is termed a 'lamella'.

\section{Canine and postcanine tooth sizes and their interactions}

The size of the permanent canines in anthropoid primates differs considerably. An estimate of this depends on how it is measured. Lucas (1981) and Lucas et al. (1986b) employed the angle of rotation of the jaw joint at which the tips of the cusps of the unworn upper and lower canines just clear each other. This indirect but dimensional measurement scales canine crown height to the size of the jaws. In most species, these angles are much larger in males than in females. The upper and lower canine tips of most female primates clear each other at about $5-7^{\circ}$ of jaw joint rota- tion (the exception in hominoids are the gibbons), while in catarrhine males the range is from about 11 to $24^{\circ}$. The lower values are found in orangutans, gorillas and chimpanzees. Lucas et al. (1986b) showed that the higher the jaw joint, the smaller are the canines in males.

The reason for this concerns the alignment of the canines at gapes at which they would be used: the higher the jaw joint, the more a lower canine moves backwards in relation to the upper, thus misaligning it during a bite. The jaw joint is relatively high in hominoids in general, and thus the canines of males might be smaller as a result. None of this, though, explains why hominin males have such small canines. Plavcan \& Van Schaik (1997) elect to use conventional measures of crown sizes, and they interpret canine size reduction in hominins in behavioural terms. Rather than resort to well-known behavioural models, we suggest that the size of the postcanine teeth might be implicated in canine reduction.

There are several theories concerning the dietary influences on postcanine tooth size in mammals. One strain of theory would have it that tooth sizes correspond to differences in the internal mechanical properties of foods; thus, for example, molar tooth sizes would co-vary with the magnitude of bite forces (Demes \& Creel, 1988; Spencer, 1999; Lucas, 2004; Grine et al. 2005). The other view, emphasized here, is that tooth size is an adaptation to the surface characteristics of foods (Lucas et al. 1986a). For the latter, though, which is based on the pattern of food comminution in modern human mastication, the pattern of adaptation is not necessarily intuitive. Large cheek teeth may be an evolutionary response, not to an enlargement in the mouthful (volume) of food taken into the mouth, but to a mouthful of small food particles (Lucas \& Luke, 1984; Lucas, 2004), where 'small particle' here means 'small by volume'. This is based on the following probabilistic argument. Food particles are not certain to be broken by postcanine teeth in any one chew because tooth surfaces only form a small proportion of the oral surface. Particles can thus get 'lost' in the mouth, and this is why the cheek muscles and the tongue play such an important role in chewing by keeping food particles between the teeth. Smaller particles have lower probabilities of being broken than larger ones. If small particles of food are ingested, and which will not be digested unless broken, one adaptation that can increase this probability is an increase in the surface area of the postcanine teeth (Lucas et al. 1986a).

Such small particles do not necessarily have to be tiny in all dimensions: they could be in 'sheet' or 'rod' form. Thus, some leaves and seeds can be considered small. One of the dominant early ideas in human evolution in fact was that hominins in general and archaic megadonts in particular were 'small object feeders' (Jolly, 1970). Despite this, there is no organized body of field data from living primates on the dimensions of food objects available for morphological correlation and so the argument cannot be taken further 


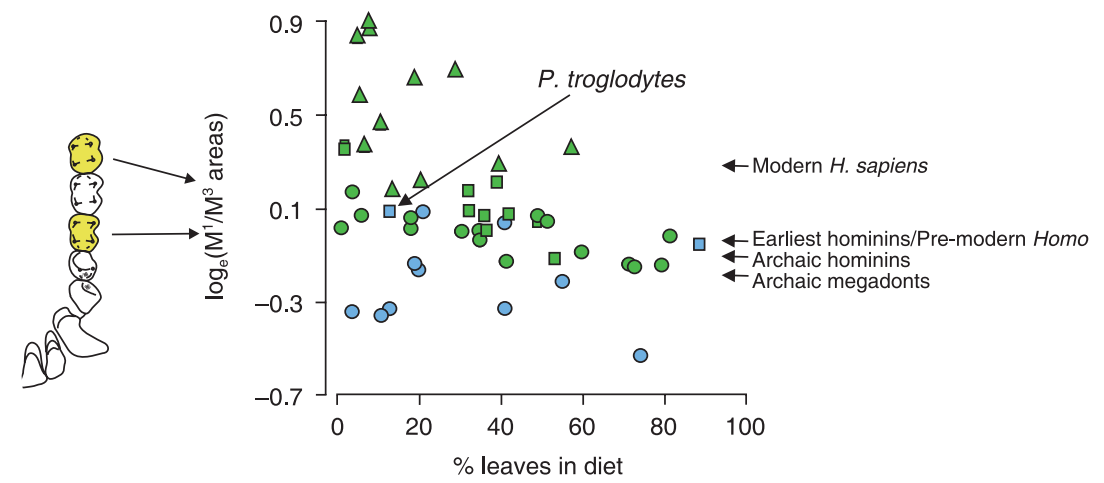

Fig. 4 The maxillary M1/M3 ratios (the ratio of the areas of the smallest rectangular box that will fit around each tooth in occlusal view) for maxillary molars in anthropoid primate species (triangles = cebids; circles = cercopithecoids; squares = hominoids) plotted against the percentage of leaves plus seeds reported in their diets (after Lucas et al. 1986c). Species shown in blue are mainly terrestrial, while those in green are predominantly arboreal. The lower the value of this ratio, the larger their molar tooth row. Approximate hominin molar ratios are also indicated. From the earliest hominins, overall molar size increased (and thus the M1/M3 ratio decreased), reaching its maximum among the archaic megadonts, overlapping those of terrestrial primates and suggesting heavy abrasive wear. In the genus Homo, molar size decreased. H. sapiens is represented by the San population. Hominin molar areas are calculated from data in van Reenen (1982) (H. sapiens); Wood \& Engleman (1988) (P. aethiopicus, P. boisei, H. habilis, H. rudolfensis and H. ergaster); White et al. (1994) (Au. afarensis); Haile-Selassie (2001) (Ar. kadabba); Ward et al. (2001) (Au. anamensis); and Moggi-Cecchi et al. (2006) (Au. africanus and P. robustus).

in a direct manner. However, Lucas et al. (1986c) constructed an argument that considered all leaves and seeds in the diet of modern primates as small objects. As an estimate of tooth size, they employed the ratio of the size of the first molar (M1) to that of the most posterior molar (M3), this ratio encapsulating much of the variation in the molar row. In Fig. 4, a regression is shown, with two influences on this ratio apparent: the amount of leaves plus seeds in the diet, and also the degree of terrestriality. The bounds on the values of M1/M3 ratio follow Teaford et al. (2002) and overlap with values for other terrestrial primates.

None of the above mentions variation in the contribution of premolars to the postcanine tooth row, but the last premolar (P4) tends to contribute more to the row when the M1/M3 ratio is higher (Lucas et al. 1986c), and this is correlated to some degree with a decrease in canine size (as assessed by the angular method above). Possibly, this is because larger premolars require the cheeks to be extended anteriorly, thus diminishing the size of the mouth slit (Lucas et al. 1986b).

\section{Jaw movement and the shape of the mandibular corpus}

In experiments on modern human subjects, Agrawal et al. (2000) found that the mastication of hard foods (foods of low $R / E$ ) was associated with larger lateral excursions of the mandible than was the case with softer foods. Such hard foods are exactly those that would be predicted above to lead to thicker enamel in order to resist deep (radial) EDJ-type cracks. To the extent that jaw structures might be linked to such dietary patterns, then it is possible that a hard diet requiring wider excursions might lead to the development of a relatively broader mandibular corpus.

\section{Predicted dietary adaptations of fossil hominins}

In terms of a general adaptive pattern, we believe that most hominins were adapted to cope with hard foods [i.e. foods with high $(E R)^{0.5}$ ] even if such items were only ingested for a small part of the year (Laden \& Wrangham, 2005). Some of the ingested objects were likely to have been very small in order to explain the extensive surface wear of the tooth surface: these particles could easily have been grit or phytoliths (Baker et al. 1959; Sanson et al. 2006) rather than foods. The low, blunt cusps of the postcanine teeth of hominins attest to this dietary specialization, as does the thickness of the enamel and the tendency for rod decussation only to be present in inner enamel. Such decussation would restrict cracking at the EDJ, while the outer radial enamel with its parallel rods might better withstand scratching (Boyde \& Fortelius, 1986).

The thickness and microstructure of enamel has long been thought to have a critical role in hominin evolution (Martin, 1985; Hlusko, 2004). One conclusion of the above review, contrary to Grine et al. (2005), is that enamel thickness may be a better guide than overall tooth size for the purpose of understanding bite forces. Even if a tooth were to be small (e.g. in modern humans where the smallest, but thickest-enamelled, molar is the M3), it would be expected to be capable of withstanding high forces (Macho \& Berner, 1993). The thickness of archaic megadont hominin molar enamel near, or at, the cusp tips may have exceeded $3.5 \mathrm{~mm}$ (Beynon \& Wood, 1987). The equations above can 
be used to generate bite force estimates. Thus, if $t=$ $3.5 \mathrm{~mm}$, then Eq. (2) for the initiation of a crack against a hard food object gives $1100 \mathrm{~N}$, while Eq. (3) gives $22000 \mathrm{~N}$. Quite how those forces would be affected by wear is difficult to say.

The ecological question is what type of foods would fit this physical description? Analysis of the dentition cannot answer this, but hominin diets are now being suggested by a range of approaches beyond the use of gross morphological evidence. For example, a combination of ecological and isotopic analyses suggests that underground storage organs were probably a key part of the diet of archaic and archaic megadont hominins (Sponheimer et al. 2005; Laden \& Wrangham, 2005), with specificity traced to corms and bulbs in the diets of specific groups of mole rats (Yeakel et al. 2007). The seeds of grasses, a diet suggested particularly for archaic megadonts (Jolly, 1970), are not excluded and the pattern of general tooth size in these hominins is consistent with this dietary scenario (Lucas, 1989).

\section{Discussion}

Other than a short section on mandibular corpus shape, this paper has kept rigidly to a discussion of the dentition. It might be felt that this ignores the constraining effect of the bony form of the jaws and face and of the bite forces that the masticatory muscles are capable of delivering. However, it can also be argued that the best estimate of bite force in a fossil would come from a structure and a tissue that is actually in contact with food particles. For hard food contacts, we offer two possible estimates of this from the thickness of the enamel.

Although every effort has been made here to provide a consistent dietary argument starting from tooth-food contacts, some readers may feel that the inferred functional advantages explored here have plausible alternative explanations. The commonest alternatives invoke developmental constraints. These ultimately link back to patterns of development proposed by D'Arcy Thompson (1917, edited and reprinted 1961), but Gould \& Lewontin (1979) are commonly cited as overall support together with the results of specific experiments. The following is an attempt to set the analysis of molar size gradients and dental reduction set out above in the context of the evolution of development.

Predictions about tooth size reduction are undeniably affected by the coordinated growth of tooth germs that produce morphological gradients of shape and size (Butler, 1939; Sofaer, 1973, 1977; Osborn, 1978). These gradients appear to result from common connection of tooth germs to the dental lamina, the downgrowth of the oral epithelium from which the enamel organs of teeth develop. Thus, for example, the molars of the mouse have been shown to grow in a series and are not individual organs (Lumsden, 1979).
The set of tooth germs connected to a strip of dental lamina can be called a family (Osborn, 1971), the number and spacing of its members being dictated by inhibitory zones around germs that prevent the fusion of neighbouring teeth (Osborn, 1978). This seems to apply to all dentitions, even those of non-mammals (Osborn, 1971). Evidence from modern human dental development suggests that mammals differ in that there are two natural breaks in the lamina, one on either side of the deciduous canine (Ooe, 1957). Experimental severing of the lamina between the molars of mice perturbs the molar size gradient, removing some developmental controls (Kavanagh et al. 2007), consistent with the above view. There are thus formed three natural tooth families: incisors, canines and postcanines, each of which has an internal gradient of size and shape. Their boundaries are clearly indicated in the erupted dentition by visible 'breaks' in form, and the order in which they form affords a basis for homology (Osborn, 1978). This being so, there would, for example, be no developmental basis for assuming that the size of each molar is independent of that of its neighbours, or that the form of the canine might influence the incisors or postcanine teeth. The apparent disparity between premolar and molar form is explained by their being from different generations. There are two generations in the mammalian dentition: deciduous and permanent. The deciduous and permanent molars appear to form a single series from the first 'deciduous' generation, while the premolars in this scheme belong to the second generation (Osborn, 1973). The difference in appearance between the last premolar and first permanent molar is due then to difference in generation, intrafamilial gradients within a single generation appearing smooth (Osborn, 1978).

This paper, however, has made no such assumptions. The sizes of incisors, canines and cheek teeth are treated as independent. The molars are treated as a set, the molar size gradient analysis of Lucas et al. (1986c) resembling that of Kavanagh et al. (2007), except that the gradient is encapsulated here in a single M1/M3 value, allowing this to be regressed against dietary variables (as in Fig. 4). The size relations of the molars are remarkably variable in primates, with (in terms of crown area), M1 $<$ M2 $<$ M3 in cercopithecoids, with $\mathrm{M} 1<\mathrm{M} 2>\mathrm{M} 3$ in apes and $\mathrm{M} 1>$ $M 2>M 3$ in modern humans. It is difficult to regard the development of molars as a growth series as in any way constraining.

\section{Acknowledgements}

We are grateful to the Anatomical Society of Great Britain and Ireland for their invitation to take part in this symposium, and to Sam Cobb for his constructive comments on a previous version of the manuscript. The participation of P.L. and B.W. was supported by George Washington University's Academic Excellence initiative, the George Washington University VPAA, by the George Washington University Professorship in Human Origins and by the ASGBI. P.C. 
is supported by a George Washington University Academic Excellence Postdoctoral Fellowship. We gratefully acknowledge the debt we owe to Brian Lawn for his participation in the research that informed this review.

\section{References}

Agrawal KR, Lucas PW, Prinz JF, Bruce IC (1997) Mechanical properties of foods responsible for resisting food breakdown in the human mouth. Archs Oral Biol 42, 1-9.

Agrawal KR, Lucas PW (2003) Mechanics of the first bite. Proc $R$ Soc Lond B270, 1277-1282.

Agrawal KR, Lucas PW, Prinz JF, Bruce IC (1998) Food properties that influence neuromuscular activity during human mastication. J Dent Res 77, 1931-1938.

Agrawal KR, Lucas PW, Bruce IC (2000) The effect of food fragmentation index on mandibular closing angle in human mastication. Archs Oral Biol 45, 577-584.

Agrawal KR, Ang KY, Sui Z, Tan HTW, Lucas PW (2008) Methods of ingestion and incisal designs. In Technique and Application in Dental Anthropology (eds Irish JD, Nelson GC), pp. 349-363. Cambridge: Cambridge University Press.

Ang KY, Lucas PW, Tan HTW (2006) Incisal orientation and biting efficiency. J Hum Evol 50, 663-672.

Asfaw B, White T, Lovejoy O, Latimer B, Simpson S, Suwa G (1999) Australopithecus garhi: a new species of early hominid from Ethiopia. Science 284, 629-635.

Ashby MF (1989) On the engineering properties of materials. Acta Met 37, 1273-1293.

Ashby MF (1999) Materials Selection in Mechanical Design, 2nd edn. Oxford: Butterworth Heinemann.

Atkins AG, Mai Y-W (1985) Elastic and Plastic Fracture. Chichester: Ellis Horwood.

Baker G, Jones LHP, Wardrop ID (1959) Cause of wear in sheeps' teeth. Nature 184, 1583-1584.

Beynon AD, Wood BA (1987) Patterns and rates of enamel growth in the molar teeth of early hominids. Nature 326, 493-496.

Boyde A (1964) The structure and development of enamel. PhD thesis, The University of London.

Boyde A, Fortelius M (1986) Development, structure and function of rhinoceros enamel. Zool J Linn Soc 87, 181-214.

Brace CL, Rosenberg K, Hunt KD (1987) Gradual change in human tooth size in the late Pleistocene and post-Pleistocene. Evolution 41, 705-720.

Brown B, Walker AC (1993) The dentition. In The Nariokotome Homo erectus Skeleton (eds Walker AC, Leakey REF), pp. 161194. Cambridge, MA: Harvard University Press.

Brunet M, Guy F, Pilbeam D, et al. (2002) A new hominid from the Upper Miocene of Chad, Central Africa. Nature 418, 145-151.

Brunet M, Guy F, Pilbeam D, et al. (2005) New material of the earliest hominid from the Upper Miocene of Chad. Nature 434, 752-755.

Butler PM (1939) Studies of the mammalian dentition. Differentiation of the postcanine dentition. Proc Zool Soc Lond B 109, 136.

D'Arcy Thompson W (1961) On Growth and Form. Cambridge: Cambridge University Press.

Dean MC, Jones MG, Pilley JR (1992) The natural history of tooth wear, continuous eruption and periodontal disease in wild shot great apes. J Hum Evol 22, 23-29.

Demes B, Creel N (1988) Bite force, diet, and cranial morphology of fossil hominids. J Hum Evol 17, 657-670.
Dominy NJ (2004) Color as an indicator of food quality to anthropoid primates: ecological evidence and an evolutionary scenario. In Anthropoid Origins: New Wisions (eds Ross C, Kay RF), pp. 615-644. New York: Kluwer Press.

Eaglen RH (1984) Incisor size and diet revised: the view from a platyrrhine perspective. Am J Phys Anthropol 69, 262-275.

Fortelius M (1985) Ungulate cheek teeth: developmental, functional and evolutionary interrelationships. Acta Zool Fenn 180, $1-76$.

Gabunia L, Vekua A (1995) A Plio-Pleistocene hominid from Dmanisi, East Georgia, Caucasus. Nature 373, 509-512.

Godfrey LR, Semprebon GM, Schwartz GT, et al. (2004) New insights into old lemurs: the trophic adaptations of the Archaeolemuridae. Int J Primatol 26, 825-854.

Gould SJ, Lewontin RC (1979) The spandrels of San Marco and the Panglossian paradigm: a critique of the adaptationist programme. Proc Roy Soc Lond B 205, 581-598.

Griffith AA (1920) Phenomena of rupture and flow in solids. Phil Trans $R$ Soc Lond A 221, 163-198.

Grine FE (1981) Trophic differences between 'gracile' and 'robust' australopithecines: a scanning electron microscope analysis of occlusal events. S Afr J Sci 77, 203-230.

Grine FE, Martin LB (1988) Enamel thickness and development in Australopithecus and Paranthropus. In The Evolutionary History of the Robust Australopithecines (ed. Grine FE), pp. 3-42. New York: Aldine de Gruyter.

Grine FE, Spencer MA, Demes B, Smith HF, Strait DS, Constant DA (2005) Molar enamel thickness in the chacma baboon, Papio ursinus (Kerr 1792). Am J Phys Anthropol 128, 812-822.

Grippo JO (1991) Abfraction: a new classification of hard tissue lesions of teeth. J Esth Dent 3, 14-18.

Haile-Selassie Y (2001) Late Miocene hominids from the Middle Awash, Ethiopia. Nature 412, 178-181.

Haile-Selassie Y, Suwa G, White TD (2004) Late Miocene teeth from Middle Awash, Ethiopia, and early hominid dental evolution. Science 303, 1503-1505.

He LH, Fujisawa N, Swain MV (2006) Elastic modulus and stressstrain response of human enamel by nano-indentation. Biomaterials 27, 4388-4398.

Hlusko LJ, Suwa G, Kono RT, Mahaney MC (2003) Genetics and the evolution of enamel thickness: a baboon model. Am J Phys Anthropol 124, 223-233.

Hlusko $U$ (2004) Integrating the genotype and phenotype in hominid paleontology. Proc Natl Acad Sci 101, 2653-2657.

Hylander WL (1975) Incisor size and diet in anthropoids with special reference to Cercopithecidae. Science 189, 1095-1097.

Hylander WL (1977) Morphological changes in human teeth and jaws in a high-attrition environment. In Orofacial Growth and Development (eds Dahlberg AA, Graber TM), pp. 301-330. Paris: Mouton.

Jolly CJ (1970) The seed-eaters: a new model of hominid differentiation. Man 5, 1-26.

Kavanagh KD, Evans AR, Jernvall J (2007) Predicting evolutionary patterns of mammalian teeth from development. Nature 449, 427-432.

Kay RF (1981) The nut crackers - a new theory of the adaptations of the Ramapithecinae. Am J Phys Anthropol 55, 141-151.

Kay RF, Grine FE (1988) Tooth morphology, wear and diet in Australopithecus and Paranthropus from southern Africa. In The Evolutionary History of the Robust Australopithecines (ed. Grine FE), pp. 427-444. New York: Aldine de Gruyter.

Kendall K (2001) Molecular Adhesion. New York: Kluwer/Plenum Press. 
Kim J-W, Bhowmick S, Chai H, Lawn BR (2007) Role of substrate material in failure of crown-like layer structures. J Biomed Mater Res Appl Biomater 81B, 305-311.

von Koenigswald W (2000) Two different strategies in enamel differentiation: Marsupialia versus Eutheria. In Development, Function and Evolution of Teeth (eds Teaford MF, Smith MM, Ferguson MWJ), pp. 252-268. Cambridge: Cambridge University Press.

Kono RT (2004) Molar enamel thickness and distribution patterns in extant great apes and humans: new insights based on a 3dimensional whole crown perspective. Anthrop Sci 112, 121146

Laden G, Wrangham R (2005) The rise of the hominids as an adaptive shift in fallback foods: underground storage organs (USOs) and australopith origins. J Hum Evol 49, 482-498.

Lawn BR (1967) Partial cone crack formation in a brittle material loaded with a sliding indenter. Proc Roy Soc Lond A299, 307316.

Lawn BR (1993) Fracture of Brittle Solids, 2nd edn. Cambridge: Cambridge University Press.

Lawn BR, Deng Y, Thompson VP (2001) Use of contact testing in the characterization and design of all-ceramic crown-like layer structures: a review. J Prosthet Dent 86, 495-510.

Lucas PW (1981) An analysis of canine size and jaw shape in some Old and New World non-human primates. $J$ Zool 195, 437-448.

Lucas PW, Luke DA (1984) Optimal mouthful for food comminution in human mastication. Archs Oral Biol 29, 205-210.

Lucas PW, Corlett RT, Luke DA (1986a) New approach to postcanine tooth size applied to Plio-pleistocene hominids. In Primate Evolution (eds Else JG, Lee PC), pp. 191-201. Cambridge: Cambridge University Press.

Lucas PW, Corlett RT, Luke DA (1986b) Sexual dimorphism of teeth in anthropoid primates. Hum Evol 1, 23-39.

Lucas PW, Corlett RT, Luke DA (1986c) Postcanine tooth size and diet in anthropoids. $Z$ Morph Anthrop 76, 253-276.

Lucas PW (1989) A new theory relating seed processing by primates to their relative tooth sizes. In The Growing Scope of Human Biology (eds Schmitt LH, Freedman L, Bruce NW), pp. 37-49. Perth: Centre for Human Biology, University of Western Australia.

Lucas PW, Corlett RT (1991) The relationship between the diet of Macaca fascicularis and forest phenology. Folia Primatol 57, 201-215.

Lucas PW, Turner IM, Dominy NJ, Yamashita N (2000) Mechanical defences to herbivory. Ann Bot 86, 913-920.

Lucas PW, Prinz JF, Agrawal KR, Bruce IM (2002) Food physics and oral physiology. Food Qual Pref 13, 203-213.

Lucas PW (2004) Dental Functional Morphology. Cambridge: Cambridge University Press.

Lucas PW, Agrawal KR, Sui ZQ, Ang KY, Tan HTW (in press a) Methods of ingestion and incisal designs. In Technique and Application in Dental Anthropology (eds Irish JD, Nelson GC). Cambridge: Cambridge University Press.

Lucas PW, Constantino P, Wood BA, Lawn BR (in press b) Dental enamel as a dietary indicator in mammals. BioEssays.

Lumsden AGS (1979) Pattern formation in the molar dentition of the mouse. J Biol Bucc 7, 77-103.

Lysell L (1958) Qualitative and quantitative determination of attrition and the ensuing tooth migration. Acta Odontol Scand 16, 267-292.

Macho GA, Berner MM (1993) Enamel thickness of human maxillary molars reconsidered. Am J Phys Anthropol 92, 189-200.

Martin LB (1985) Significance of enamel thickness in hominoid evolution. Nature 314, 260-263.
Martin LB, Olejniczak AJ, Maas MC (2003) Enamel thickness and microstructure in pitheciin primates, with comments on dietary adaptations of the middle Miocene hominoid Kenyapithecus. J Hum Evol 45, 351-367.

McHenry HM (2002) Introduction to the fossil record of human ancestry. In The Primate Fossil Record (ed. Hartwig WC), pp. 401406. Cambridge: Cambridge University Press.

Moggi-Cecchi J, Grine FE, Tobias PV (2006) Early hominid dental remains from Members 4 and 5 of the Sterkfontein Formation (1966-1996 excavations): catalogue, individual associations, morphological descriptions and initial metrical analysis. $J$ Hum Evol 50, 239-328.

Molnar S, Gantt DG (1977) Functional implications of primate enamel thickness. Am J Phys Anthropol 46, 447-454.

Okasaki K, Nishimura F, Nomoto S (1989) Fracture toughness of human enamel. Shika Zairyo Kikai 8, 382-387.

Ooe T (1957) On the early development of human dental lamina. Okajimas Folia Anat Jpn 30, 197-210.

Osborn JW (1969) Dentine hardness and incisor wear in the beaver (Castor fiber). Acta Anat 72, 123-132.

Osborn JW (1971) The ontogeny of tooth succession in Lacerta vivipara Jacquin (1787). Proc Roy Soc Lond B 179, 261-289.

Osborn JW (1973) Variation in structure and development of enamel. In Dental Enamel Oral Sciences Reviews, Vol. 3 (eds Melcher AH, Zarb, GA), pp. 3-83. Copenhagen: Munksgaard.

Osborn JW (1978) Morphogenetic gradients: fields versus clones. In Development, Function and Evolution of Teeth (eds Butler PM, Joysey KA), pp. 171-213. New York: Academic Press.

Osborn JW (1981) Dental Anatomy and Embryology, Vol. 2. A Companion to Dental Studies. Oxford: Blackwell.

Osborn JW, Baragar FA, Grey P (1987) The functional advantage of proclined incisors in man. Mem Mus Nat d'Hist Nat Paris C 53, 445-458.

Plavcan JM, Van Schaik CP (1997) Interpreting hominid behavior on the basis of sexual dimorphism. J Hum Evol 32, 345-374.

Popowics TE, Rensberger JM, Herring SW (2001) The fracture behavior of human and pig molar cusps. Arch Oral Biol 46, 1-12.

Popowics TE, Rensberger JM, Herring SW (2004) Enamel microstructure and microstrain in the fracture of human and pig molar cusps. Arch Oral Biol 49, 595-605.

Qasim T, Ford C, Bush MB, Hu X, Malament KA, Lawn BR (2007) Margin failures in brittle dome structures: relevance to failure of dental crowns. J Biomed Mater Res Appl Biomater 80B, 7885.

Rasmussen ST, Patchin RE, Scott DB, Heuer AH (1976) Fracture properties of human enamel and dentine. J Dent Res 55, 154164.

van Reenen JF (1982) The effects of attrition on tooth dimensions of San (Bushmen). In Teeth: Form, Function and Evolution (ed. Kurtén B), pp. 182-203. New York: Columbia University Press.

Rensberger JM, von Koenigswald W (1980) Functional phylogenetic interpretation of enamel microstructure in rhinoceroses. Paleobiology 6, 447-495.

Renson CE, Braden M (1971) The experimental deformation of human dentine by indenters. Arch Oral Biol 16, 563-572.

Rhee Y-W, Kim H-W, Deng Y, Lawn BR (2001) Contact-induced damage in ceramic coatings on compliant substrates. $J \mathrm{Am}$ Ceram Soc 84, 1066-1072.

Ross CF (2000) Into the light: the origin of Anthropoidea. Ann Rev Anthropol 29, 147-194.

Rudas M, Qasim T, Bush MB, Lawn BR (2005) Failure of curved brittle layer systems from radial cracking in concentrated surface loading. J Mater Res 20, 2812-2819. 
Sanson GD, Kerr SA, Gross KA (2006) Do silica phytoliths really wear mammalian teeth? J Arch Sci 34, 526-531.

Scott RS, Ungar PS, Bergstrom TS, et al. (2005) Dental microwear texture analysis shows within-species diet variability in fossil hominins. Nature 436, 693-695.

Sharp SJ, Ashby MF, Fleck NA (1993) Material response under static and sliding indentation loads. Acta Met Mater 41, 685-692.

Sherwood CC, Subiaul F, Zawidzki TW (2008) A natural history of the human mind: tracing evolutionary changes in brain and cognition. J Anat 212, 426-454.

Smith TM, Martin LB, Leakey MG (2003) Enamel thickness, microstructure and development in Afropithecus turkanensis. J Hum Evol 44, 283-306.

Smith TM, Olejniczak AJ, Martin LB, Reid DJ (2005) Variation in hominoid molar enamel thickness. J Hum Evol 48, 575-592.

Sofaer JA (1973) A model relating developmental interaction and differential evolutionary reduction of tooth size. Evolution 27, 427-434.

Sofaer JA (1977) Co-ordinated growth of successively initiated tooth germs in the mouse. Arch Oral Biol 22, 71-72.

Spencer MA (1999) Constraints on masticatory system evolution in anthropoid primates. Am J Phys Anthropol 108, 483-506.

Sponheimer M, Lee-Thorp JA, de Ruiter D, et al. (2005) Hominins, sedges, and termites: new carbon isotope data from Sterkfontein valley and Kruger National Park. J Hum Evol 48, 301-312.

Spoor F, Leakey MG, Gathogo PN, et al. (2007) Implications of new early Homo fossils from lleret, east of Lake Turkana, Kenya. Nature 448, 688-691.

Sui ZQ, Agrawal KR, Corke H, Lucas PW (2006) Biting efficiency in relation to incisal angulation. Arch Oral Biol 51, 491-497.

Suwa G, Kono RT, Katoh S, Asfaw B, Beyene Y (2007) A new species of great ape from the late Miocene epoch in Ethiopia. Nature 448, 921-924.

Teaford MF (1988) A review of dental microwear and diet in modern mammals. Scanning Microsc 2, 1149-1166.

Teaford MF (1994) Dental microwear and dental function. Evol Anthropo/ 3, 17-30.

Teaford MF, Ungar PS (2000) Diet and the evolution of the earliest human ancestors. Proc Natl Acad Sci 97, 13506-13511.

Teaford, MF, Ungar PS, Grine, FE (2002) Paleontological evidence for the diets of African Plio-Pleistocene hominins with special reference to early Homo. In Human Diet: Its Origin and Evolution (eds Ungar PS, Teaford MF), pp. 143-166. Westport: Bergin \& Garvey.

Townshend GC, Brown T (1983) Molar size sequence in Australian aboriginals. Am J Phys Anthropol 60, 69-74.

Ungar PS (1992) Incisal microwear and feeding behavior of four sumatran anthropoids. PhD thesis, State University of New York at Stony Brook.

Ungar PS (1996) Relationship of incisor size to diet and anterior tooth use in sympatric Sumatran anthropoids. Am J Primato/ 38, 145-146.
Ungar PS, Teaford MF (2002) Human Diet: Its origin and Evolution. Westport: Bergin and Garvey.

Ungar PS, Grine FE, Teaford MF (2006) Diet in early Homo: a review of the evidence and a new model of adaptive versatility. Ann Rev Anthropol 35, 209-228.

Ungar PS (2007) The Evolution of Hominin Diets: The Known, the Unknown, and the Unknowable. Oxford: Oxford University Press.

Vincent JFV, Saunders DEJ, Beyts P (2002) The use of stress intensity factor to quantify 'hardness' and 'crunchiness' objectively. $J$ Texture Stud 33, 149-159.

Vogel ER, van Woerden JT, Lucas PW, et al. (in press) Functional ecology and evolution of hominoid molar enamel thickness: Pan troglodytes schweinfurthii and Pongo pygmaeus wurmbii. J Hum Evol.

Walker AC (1981) Diet and teeth: dietary hypotheses and human evolution. Phil Trans Roy Soc Lond B292, 57-76.

Ward CV, Leakey MG, Walker A (2001) Morphology of Australopithecus anamensis from Kanapoi and Allia Bay, Kenya. J Hum Evol 41, 255-368.

Waters NE (1980) Some mechanical and physical properties of teeth. In The Mechanical Properties of Biological Materials (eds Vincent JFV, Currey JD), pp. 99-135. Cambridge: Cambridge University Press.

White TD, Suwa G, Asfaw B (1994) Australopithecus ramidus, a new species of early hominid from Aramis, Ethiopia. Nature 371, 306-312.

Wood BA, Stack CG (1980) Does allometry explain the differences between 'gracile' and 'robust' australopithecines? Am J Phys Anthropol 52, 55-62.

Wood BA, Abbott SA (1983) Analysis of the dental morphology of Plio-Pleistocene hominids. I. Mandibular molars: crown area measurements and morphological traits. J Anat 136, 197219.

Wood BA, Abbott SA, Graham SH (1983) Analysis of the dental morphology of Plio-Pleistocene hominids. II. Mandibular molars - study of cusp areas, fissure pattern and cross sectional shape of the crown. J Anat 137, 287-314.

Wood BA (1984) Tooth size and shape and their relevances to studies of human evolution. Phil Trans R Soc Lond B292, 57-64.

Wood BA, Engleman CA (1988) Analysis of the dental morphology of Plio-Pleistocene hominids. V. Maxillary postcanine tooth morphology. J Anat 161, 1-35.

Wood B (2002) Hominid revelations from Chad. Nature 418,133135.

Wood B, Lonergan N (2008) The hominin fossil record: taxa, grades and clades. J Anat 212, 354-376.

Yeakel JD, Bennett NC, Koch PL, Dominy NJ (2007) The isotopic ecology of African mole rats informs hypotheses on the evolution of human diet. Proc $R$ Soc Lond B274, 1723-1730.

Zingeser MR (1969) Cercopithecoid honing mechanisms. Am J Phys Anthropol 31, 205-214. 